\title{
DOCUMENTO
}

\section{DISCURSOS PROFERIDOS PELO REI D. PEDRO V NAS SESSÕES SOLENES DE ATRIBUIÇÃO DE PRÉMIOS NA ESCOLA REAL DE MAFRA (1858-1860)}

DOI: http://dx.doi.org/10.1590/2236-3459/82160

\begin{abstract}
KING PEDRO THE $V^{\text {th' }} S$ SPEECHES DURING THE SOLEMN SESSIONS OF THE AWARD OF PRIZES IN "ESCOLA REAL DE MAFRA" (1858-1860)
\end{abstract}

\author{
Carlos Manique da Silva' \\ 'Universidade de Lisboa (Ulisboa), Lisboa, Portugal
}

$\cos 80$

\section{Introdução}

$\mathrm{N}$

ão obstante ter tido uma vida breve, o rei D. Pedro V (1837-1861) ficou conhecido por dedicar atenção à causa pública, manifestando especial interesse pelo tema da educação. Culto ${ }^{1}$, de grande capacidade intelectual e, além do mais, viajado - realizou, em 1854-1855, o grand tour (uma prática de educação comum entre a nobreza europeia), visitando então Itália, Suíça, Inglaterra, Bélgica, Holanda, Alemanha e França -, foi capaz de concretizar, justamente no campo educativo, alguns projetos de inegável mérito. Para isso concorreu, também, a circunstância de o seu reinado ter sido um dos mais consensuais da centúria de Oitocentos. (TORGAL, 1993). Citem-se, tão-somente, duas realizações: a criação da Escola Real de Mafra², em 1855, ano em que D. Pedro V começou a governar; e, seis anos mais tarde, a inauguração do Curso Superior de Letras, que esteve na origem da Faculdade de Letras da Universidade

\footnotetext{
${ }_{1}^{1}$ À época, D. Pedro V terá sido um dos soberanos mais cultos da Europa. (ANDRADE FERREIRA, 1862).

2 A Escola estava sediada numa das dependências do Palácio de Mafra, nela sendo ministrada a instrução primária elementar e superior.
} 
de Lisboa, fundada em 1911. (COUVANEIRO, 2012). De resto, o soberano deixou boa impressão no seio da instrução pública. Em novembro de 1864, por exemplo, celebrou-se na capela da Escola Normal de Lisboa uma missa em sua memória; algo que parece terse institucionalizado durante alguns anos. (SILVA, 2003). Por outro lado, um dos vultos da Pedagogia portuguesa, António Feliciano de Castilho, dedicou a segunda edição do "Método Português" ao infausto monarca. O próprio D. António da Costa, que ocupou a primeira pasta da Instrução Pública existente em Portugal, teceu-lhe encómios vários. (COSTA, 1871).

Com a divulgação de um conjunto de discursos escritos por D. Pedro V, pretendese, no fundamental, contribuir para o conhecimento do seu pensamento pedagógico. Refirome a três discursos redigidos pelo próprio punho do rei nos anos de 1858 e de 1860, todos autógrafos, destinados a ser lidos num contexto muito particular: as sessões solenes de entrega de prémios aos alunos da Escola Real de Mafra ${ }^{3}$. De certo modo estamos perante documentos epistolares, no sentido em que encerram um face-a-face: entre quem lê um texto, dando-se a conhecer, e os destinatários (alunos e pais), os quais se sentem "olhados"; uma perspetiva que, no caso em questão, se afasta, forçosamente, da metáfora da carta como "conversa entre ausentes". (PEIXINHO, 2013).

Há algumas ideias e princípios que emergem do conjunto de cartas agora publicado. Parece-me importante destacá-los, deixando, depois, ao leitor a possibilidade de as ler atentamente e de fazer a sua própria análise. Um dos pensamentos estruturantes da ação educativa de $\mathrm{D}$. Pedro $\mathrm{V}$ é o de que as classes populares precisam de ser instruídas (crença na "regeneração do povo" através da escola). Expressa-o, implicitamente, na sessão de entrega de prémios realizada na Escola Real de Mafra, no dia 26 de agosto de 1858, ao afirmar: "tenho a simplicidade de acreditar que as escolas [...] hão de formar a sociedade em que eu espero viver os meus últimos dias"4. Uma ideia de sociedade que é alimentada pela seguinte visão: "julguei que a Escola devia ensinar aos homens a união, ensinando-lhes a necessidade, que eles, qualquer que seja a sua posição recíproca, têm uns dos outros" 5 . Nesse pressuposto o monarca vai mais longe, ao ver na escola a forma de esbater as diferenças de nascimento (condição social). De facto, considera "as inteligências dos alunos como páginas brancas entre as quais se distinguiriam aquelas em que mais rapidamente ou melhor pudesse escrever o mestre" 6 . Perspetiva, assim, a escola como "uma pequena democracia, do seio da qual a cada momento nasce uma aristocracia"7. É essa, aliás, a filosofia que preside à fundação da Escola Real de Mafra; instituição educativa sob proteção régia, mas que, efetivamente, faz as vezes de escola pública - não dirigida, portanto, a um estrato social específico. (SILVA, 2003).

Outra linha de força do pensamento pedagógico de $\mathrm{D}$. Pedro $\mathrm{V}$ prende-se com a emulação. Trata-se de um aspeto muito valorizado, conforme transmite ao príncipe Alberto, em carta datada de 7 de março de 1859, na referência à Escola Real de Mafra: "Sou eu

\footnotetext{
${ }^{3}$ Os referidos documentos encontram-se no Arquivo Municipal de Mafra (AMM), fundo Escola Real de Mafra. $\mathrm{Na}$ transcrição optámos por atualizar a grafia e a pontuação, manter as maiúsculas e minúsculas iniciais e desdobrar as abreviaturas.

${ }^{4}$ AMM, Escola Real de Mafra, discurso de D. Pedro V, 26 de agosto de 1858, fl. 3v. Uma ideia que é abertamente manifestada por D. Pedro V ao seu tio, o príncipe Alberto, em carta datada de 17/12/1855, na qual refere: "Em Portugal há uma grande necessidade em educar os portugueses". (LEITÃO, 1954, p. 95).

${ }^{5}$ AMM, Escola Real de Mafra, discurso de D. Pedro V, 14 de março de 1858, fl. 3v.

6 Idem, Ibidem, fl. 4.

7 Idem, Ibidem, fl. 4.
} 
próprio quem distribui todos os anos os prémios aos melhores alunos, e noto que se está a começar a revelar um verdadeiro espírito de competição entre as crianças relativamente a estas distinções". (LEITÃO, 1954, p. 224). Do seu ponto de vista, é o princípio da emulação (e não outro qualquer) que deve presidir à distinção entre alunos. Porém, não deixa de ser paradoxal que um sistema de ensino alicerçado na ideia de competição, conforme sucedeu com a Escola Real de Mafra, seja capaz de criar valores de unidade e de inequívoca coesão de grupo. (SILVA, 2003). Mas é bom que se entenda que o reconhecimento público aos melhores alunos nas sessões de entrega de prémios pressupõe a valorização de todo o processo educativo (e não apenas esse ato solene). Disso mesmo dá conta D. Pedro V, ao dirigir-se, especificamente, aos pais dos alunos:

Aos pais dos alunos pediria eu que concorressem menos às festividades escolares, nas quais se expõem a dissabores que na sua mão estaria muitas vezes evitar, e frequentassem mais a aula nos dias ordinários; que não contassem só os prémios concedidos ou recusados no fim do ano, mas os títulos que, durante ele, dão direito a essas distinções ${ }^{8}$.

Por outro lado, interessa dizer que o soberano conhece bem os debates pedagógicos da época. Por exemplo, tem perfeita noção dos modos de ensino (individual, simultâneo, mútuo e misto) e das implicações resultantes da aplicação de cada um deles. Apresenta, de resto, justificações a respeito da organização pedagógica seguida na Escola Real de Mafra. Com efeito, no último discurso que proferiu no mencionado instituto de ensino, corria o mês de agosto de 1860, revela ter sido impossível adotar em exclusivo o ensino simultâneo. O óbice, o excessivo número de alunos. A solução adotada passa pela utilização de alunos mais adiantados (decuriões) no processo de ensino, traduzindo, na prática, a conjugação dos modos simultâneo e mútuo (modo misto). Note-se que o recurso aos decuriões tem por objetivo dar maior eficiência ao ensino, encerrando, ao mesmo tempo, uma visão de sociedade meritocrática. Atente-se na seguinte passagem: "fazer dos decuriões [...] um elemento de decomposição do ensino e uma aristocracia amovível completando o sistema disciplinar, são necessidades que, de algum modo, se prejudicam" ${ }^{\text {. }}$.

No seu conjunto, os três discursos do monarca elucidam bem o vanguardismo do seu pensamento pedagógico, o qual se traduz, para além do que foi sendo referido, em algumas ideias ousadas. Cite-se apenas a seguinte: a vontade de conceder ao ensino público a seleção dos docentes (cf. Documento 3).

A sua ação - que toma forma na criação de instituições de referência (nomeadamente, a Escola Real de Mafra e o Curso Superior de Letras) - contrasta, ao mesmo tempo, com a extrema dificuldade em propagar a modernidade no panorama nacional $^{10}$.

\section{Referências}

ANDRADE FERREIRA, José Maria de. Reinado e últimos momentos de D. Pedro V. Lisboa: Livraria de António Maria Pereira, 1862.

\footnotetext{
${ }^{8}$ AMM, Escola Real de Mafra, discurso de D. Pedro V, 26 de agosto de 1860, fl. 2.

9 Idem, Ibidem, 26 de agosto de 1860, fl. 1 v.

10 É, certamente, útil ficar com a seguinte ideia: em Portugal, cerca de 1870, as taxas de escolarização não ultrapassariam em muito os $10 \%$ da população em idade escolar. (NÓVOA, 2005).
} 
COSTA, D. António da. Historia da instrucção popular em Portugal. Lisboa: Imprensa Nacional, 1871.

COUVANEIRO, João. O Curso Superior de Letras (1861-1911). Nos Primórdios das Ciências Humanas em Portugal. 2012. Tese (Doutorado em História) - Faculdade de Letras da Universidade de Lisboa, Lisboa, 2012.

LEITÃO, Ruben Andresen (tradução). Cartas de D. Pedro V ao Príncipe Alberto. Lisboa: Fundação da Casa de Bragança/Portugália Editora, 1954.

NÓVOA, António. Evidentemente. Porto: Edições ASA, 2005.

PEIXINHO, Ana Teresa. As cartas de Soror Mariana: o epistolar como discurso da paixão. Biblos, Coimbra, v. XI, p. 39-59, 2013.

SILVA, Carlos Manique da. Uma instituição de ensino fundada por D. Pedro V: a Escola Real de Mafra. História, Porto, v. 4, p. 275-295, 2003.

TORGAL, Luís Reis. Instrução Pública - O sentido e a força de um conceito liberal. In: MATOSO, José (Dir.). História de Portugal. Lisboa: Editorial Estampa, v. 5, 1993. p. 609651.

\section{Documento 1}

Discurso [de D. Pedro V] pronunciado por ocasião da distribuição de prémios na Escola de Mafra, em 14 de março de 1858 [fl. 2]

Dois anos de existência são entre nós suficiente prova da vitabilidade ${ }^{11}$ de uma instituição. Quinze dias leva, por via de regra, a envelhecer tudo quanto ao nascer mereceu algum favor pelo simples facto da novidade.

É pois na virtude intrínseca da instituição que devemos procurar as causas da vida, dissemelhante da que arrastam entre nós tantos institutos de igual natureza, que se nota na Escola de Mafra.

Modesta chama, para assim dizer, encarcerada no mais gigantesco dos monumentos, que entre nós deixou um passado, de que tantos ainda não se desacostumaram a afastar os olhos, poderá dizer-se que ela simboliza o futuro, débil e apenas nascido, acabrunhado pelo peso do passado.

E, contudo, se caísse o monumento de pedra que parece indestrutível, o tempo e o bom senso popular poupariam a Escola, que ficaria de pé no meio das ruínas. $O$ monumento deslumbrava, a Escola civilizava instruindo. [fl. 2 v.]

Alguém, porventura, me atribuirá a honra dos resultados até hoje obtidos. A lisonja, que não distingue, passa ao pé do mestre, que colheu os louvores para o fundador, e independente dele vem enfeixar o merecido com o imerecido para lançá-lo aos pés daquele, a quem se crê necessário atribuir o bem, porque se espera dele o benefício.

Antes pois de dizer algumas palavras sobre a natureza desta instituição, definirei o que pertence ao fundador, e o que pertence ao mestre.

Ao fundador pertence o pensamento, bom ou mau, seguindo aqueles que creem

${ }^{11}$ Quer significar viabilidade. 
ou deixam de crer na utilidade da evangelização do ensino elementar. Construí a máquina, do mestre dependia que ela funcionasse.

Criando a Escola de Mafra obedeci a dois deveres, ou antes obedeci a um só dever, que se divide pelos dois motivos, que poderiam determinar-me a ceder à instrução um aposento em minha casa.

Olhei primeiro para o meu dever, como soberano, e, [fl. 3] sobretudo, para o caráter de permanência da minha pouca invejável autoridade. Julguei que era compreendê-lo o fazer servir a influência, que eu pudesse derivar da minha posição, como soberano, dos meus atos, como homem, em promover os melhoramentos que carecem de uma iniciativa moral, cuja continuidade se quebra tantas vezes pelas mutações da cena política. Entendi que era aplicar bem os meios de ação, que a Constituição deixa ao soberano, o chamar a instrução a criar esse bom senso universal que evita os excessos das paixões populares por uma parte, e por outra os da autoridade soberana, provocadores uns dos outros, e conseguintemente inocentes e criminosos ao mesmo tempo.

Depois, pareceu-me que a civilização bate a todas as portas, e que ela pede esmola a todos. Pareceu-me que o progresso dá obra para todos, e reclamei para mim também o nome de operário. Tantos negam à civilização e ao progresso o seu óbolo e o seu abraço, porque não têm [fl. 3 v.] nem meios nem força para alcançar uma glória que não querem repartir, porque pensam (fatal engano!) que a glória se diminui pela divisão! Esses que ignoram o valor da associação, ainda mesmo associados, seriam incapazes de produzir coisa alguma. Associariam acaso os seus capitais, sem associarem a inteligência, 0 coração e a vontade. Esquecem que a sociedade é responsável pelos males que sofre, que ela não deveria recorrer ao Estado, quer dizer, à necessidade de pagar o imposto forçado, sem ter pago esse imposto voluntário, cujo emprego o contribuinte tem o direito e a possibilidade de fiscalizar a cada momento.

Julguei que a Escola devia ensinar aos homens a união, ensinando-lhes a necessidade, que eles, qualquer que seja a sua posição recíproca, têm uns dos outros. Julguei que o primeiro passo dado para este fim era fazer com que eles se conhecessem desde a infância, sem que os afastassem as distinções a que tão geralmente se liga a tão funesta ideia de separação. Assim procurei que aqueles [fl. 4] que no mundo acham bastante ocasião de fazer sentir, no que tem de necessário ou de irritante as distinções do nascimento, do acaso ou da fortuna, fossem iguais diante da justiça do mestre e da disciplina escolar.

Considerei as inteligências dos alunos como páginas brancas, entre as quais se distinguiriam aquelas em que mais rapidamente ou melhor pudesse escrever o mestre. Considerei a Escola como uma pequena democracia, do seio da qual a cada momento nasce uma aristocracia. Mas as mesmas distinções, que o merecimento tivesse de criar nela, quis eu que fossem um princípio de emulação, sem jamais se converterem em um princípio de inveja. Por isso são elas o alvo de um constante certame.

Esse fim creio tê-lo alcançado, graças, sobretudo, ao mestre, que compreendeu não somente o espírito da instituição, à qual ele deu vida, senão também o dever de fazer amar e respeitar a sua magistratura sem carecer do auxílio do temor. [fl. 4 v.]

Lembrai-vos, alunos da Escola de Mafra, no decurso da vossa vida, do dia de hoje. Nele criastes a alegria em três espécies de corações, feitos igualmente para senti-la, mas feitos ao mesmo tempo para compreendê-la diversamente - $\mathrm{O}$ fundador da Escola pede- 
vos que não o esqueçais - Vossos pais viram que a índole da organização da Escola, que o seu ensino chamando o espírito a educar o coração, não frustraram a confiança que nela depositaram - Para os mestres, para os que em nome da religião e da ciência substituíram a família no mister da educação, peço a gratidão dos seus discípulos.

Mafra, 14 de março de 1858

D. Pedro V

\section{Documento 2}

Discurso pronunciado por S. Majestade El Rei o Senhor D. Pedro V por ocasião da distribuição de prémios na Escola Real de Mafra, em 26 de agosto de 1858, à qual presidiu também S. Majestade a Rainha a Senhora D. Estefânia [fl. 2]

São tantas as razões que podem aconselhar a criação de uma escola, que seria não acabar enumerá-las todas.

Quando, pela última vez, distribuí aos alunos da Escola de Mafra os prémios, que conquistaram com a aplicação e bom comportamento, falei de algumas. Hoje acrescentarei outras, não todas, que não é dado tê-las presentes a um tempo, mas aquelas que me pareceram mais ponderosas.

Para ser sincero direi ainda que não foram estas as que realmente inspiraram o pensamento da criação deste presepe da redenção intelectual das novas gerações, o qual por si pouco valeria se a cegueira de pai me não levasse a crer que ele vale muito pelo espírito da sua instituição.

Mas se as razões de que hoje me ocuparei não têm realmente um direito de paternidade sobre esta Escola, podem elas reclamar o direito de adoção. Por terem vindo tarde, por terem acompanhado a reflexão, não são elas menos fortes que as que se geraram da ideia um pouco vaga, nascida mais do coração que da cabeça, de que era um serviço abrir mais uma escola, sobretudo arrancar ao Estado uma parte desse domínio, que se justifica e ao mesmo tempo se deplora.

As sociedades humanas apresentam-se-nos irremissivelmente debaixo de três aspetos diferentes. [fl. $2 \mathrm{v}$.]

Vemo-las lutar, pela sua inércia, contra os esforços do poder para lhes fazer aceitar os melhoramentos, reclamados mais ainda pelo parentesco moral dos povos entre si, que pelas necessidades mesmas das sociedades. Esse estado avizinha-se da barbárie, se é que ele não é a barbárie mesma.

Depois, as boas ideias, à força de serem repetidas, começam a ser escutadas, aquilo que anos antes era utopia, subitamente deixa de sê-lo; aceita-se passivamente o que passivamente se rejeitava, e a civilização começa a identificar-se com os hábitos populares, com a índole mesma dos povos.

Como se operam essas revoluções; até que ponto sejam (sic) o resultado da ação 
do poder, que se envergonha de ficar atrás do seu tempo, ou da sociedade, que começa a sentir esse pudor, que é a maturidade para uma ação mais energicamente progressiva não é aqui lugar de dizê-lo. Nem seria vergonha ignorá-lo, quando tantos o explicam diversamente.

É difícil discriminar o que, nos resultados da vida social, pertence a cada uma das duas tendências que, nas sociedades que se chamam povos, se digladiam, se exterminam e se vencem temporariamente, e que eternas como a humanidade mesma, renascem quando as crêramos mortas.

De um resultado, cada povo conserva no seu desenvolvimento, [fl. 3] no que chamamos a sua civilização, um caráter de individualidade, diante do qual falha tantas vezes a razão do legislador demasiadamente impaciente. De outro lado, cada povo participa da natureza comum da humanidade, com quem mais frequentemente caminha 0 legislador. Se a sua natureza própria, por vezes, o conserva no atrasamento, a humanidade o arrasta consigo, e lhe ordena que progrida. Daí os frequentes desacordos entre a condição real dos povos e a civilização que lhes formoseia a superfície; entre a massa que espera mas não crê, e as classes e os indivíduos que creem e esperam.

Ninguém contesta que os esforços, ainda extemporâneos dos governantes por comunicar movimento à inércia mesma, têm por efeito dar à sociedade, no momento da sua maioridade, os instrumentos de transformação que, aliás, ela mesma teria de construir. Não se simulam contudo oficialmente fenómenos da vida social, nem se vacina a civilização em um corpo mal disposto a deixar-se contaminar do bem e do mal que a civilização em si encerra.

O que aqui reconheço como facto, aceito-o facilmente como teoria.

A civilização existe, para mim, no estado em que a sociedade [fl. 3 v.] e o poder contendem entre si para se substituírem e se excluírem mutuamente no cuidado dos interesses da comunidade.

A esse estado desejo que cheguemos, e tenho a simplicidade de acreditar que as escolas - quando as escolas preencherem em Portugal a sua grande missão religiosa, moral e política - hão de formar a sociedade em que eu espero viver os meus últimos dias. Volver-se-iam em consolação os trabalhos, os dissabores (e, ser-me-á permitido acrescentar, as desesperações?) que custa o ser procurador dessas crianças de quem um escritor eminente disse "que já são homens".

Não sei como se compadeçam o desfavor real, que o ensino popular encontra no fundo das declamações, que lhe prometem nova vida, e a convicção tão universal - tão triste para nós e tão lisonjeira para as que nos hão de suceder - da necessidade de quebrar a continuidade moral entre a antiga e a nova humanidade. E, contudo, essa obra tentada e malograda no século XVIII, ou se há de servir da escola primária, ou é mais um desses sonhos desanimadores com que se iludem os homens.

Tentamos, disse eu, o que o século XVIII tentara, mas entre uma e outra época a diferença é grande.

Substituímos à filosofia que exalta para abater, a [fl. 4] religião que nos humilha e nos atenta; e em vez de pretendermos comprimir os novos homens nos antigos moldes, entregamo-los às noções despretensiosas com que os lançamos no mundo. Entendemos que instruir é educar, e não nos parece necessário lisonjear pretensões de classes por meio 
de uma distinção a que não reconhecemos razão de ser. Formando o espírito, formamos o coração, e não nos lembramos de fazer da escola, que instrui com a doutrina um perfeito sucedâneo da família, que instrui pelo exemplo.

Entendemos, e creio que entendemos bem, que pelo que pode ensinar a escola primária começa e acaba a ciência humana e que, nas noções com que daí sai o mancebo, ele encontra - tolere-se a expressão - o gérmen e como que a síntese do que podem ensinar as Academias. Por isso, as boas escolas primárias dispensam, para muitos, as Academias.

Não me compete dizer bem da Escola de Mafra. Eu, que confio na regeneração do povo, que se diz rude, porque ainda não rompeu o invólucro de qualidades puras e nobres, não posso rejeitar os sufrágios que a minha obra recolhe com o número crescente de Alunos. E quando estes por tal forma se encarregam do louvor de seus Mestres, não poderei hoje dispensar-me de repetir o que há meses dizia dos que deram [fl. 4 v.] o ser ao meu pensamento?

Alunos da Escola de Mafra! Foi a Rainha quem desejou distribuir-vos hoje as recompensas que alguma coisa significam, quando tocam a poucos de entre muitos.

Não perdeis em terdes mais uma Mãe que, como as vossas, folga com as vossas primeiras satisfações, satisfações de orgulho, se não vos lembrasse que os talentos são mais acaso do que merecimento.

Mafra, 26 de agosto de 1858

D. Pedro V

\section{Documento 3}

\section{Discurso pronunciado por S. Majestade El Rei o Senhor D. Pedro V por ocasião da distribuição de prémios na Escola Real de Mafra, em 26 de agosto de 1860}

Num ponto existe verdadeira unidade de pensamento nos que se preocupam com o porvir das sociedades, em se empenharem todos, conquanto diversas se possam considerar as tensões, pelo alargamento da área conquistada pela instrução popular.

Não quisera que concordassem tão facilmente; quisera que a arma não deixasse de denunciar a mão que a maneja, e penso que os princípios, verdadeiros ou falsos, que entre si disputam o governo da educação nacional, ganhariam mais em se definirem com sinceridade que em se matizarem enganosamente, apelando do dia de hoje, que é sempre para o dia de amanhã, que é nunca.

Julgo ter feito bom serviço na instituição da Escola de Mafra. Desejei que fosse norma e exemplo. Melhor serviço entendo ter prestado, mantendo-a neutral no meio das contendas que, do ensino primário e do secundário, tendem a fazer um problema tão delicado e árduo.

Esforçando-me por vencer sucessivamente as dificuldades que, de comum, 
embargam os primeiros passos a instituições desta natureza, [?] meus quase sempre de si mesmos, não pretendo apresentar isenta de defeitos a minha feitura, ou embargar à crítica o seu voto sobre o verdadeiro valor dos resultados, que de ano para ano parecem afracar.

De uma parte da crítica me encarregarei eu mesmo, que se há faltas a confessar, quase todas se explicam e se desculpam.

Recordarei a origem da Escola, em que se fundiu quase imediatamente a antiga aula régia. Dela recebeu um contingente valioso de alunos medianamente desenvolvidos, e destes saiu, nos primeiros tempos, grande parte dos candidatos às distinções escolares. Esgotada esta camada, que pesava sobre as inferiores, principiou a Escola a operar exclusivamente sobre a matéria rude.

Cumpre em seguida atender à desproporção temporária entre as aspirações do ensino e os meios de realizá-las. Estão irmanados [?] uma unidade que não podia deixar de ser transitória, dois institutos de índole absolutamente distinta - uma escola elementar [fl. 1 v.] e uma escola de segundo grau. Presidiu até agora a ambos um só mestre insuficientemente secundado pelos ajudantes tirados de entre os alunos mais distintos.

Era impraticável o ensino simultâneo, na sua aceção mais rigorosa, com uma população, que raras vezes desceu de setenta alunos, desiguais na idade, tendo de repartir-se por um número excessivo de classes, desde o alfabeto até às noções elementares da geometria aplicada. Era difícil estabelecer o ensino mútuo, defetivo em si, mas necessário nas aulas superabundantemente povoadas, sem que grande parte do tempo se gastasse no lavor incessante de formar decuriões.

Fazer dos decuriões, ao mesmo tempo, um elemento de decomposição do ensino e uma aristocracia amovível completando o sistema disciplinar, são necessidades que, de algum modo, se prejudicam, e que não é de admirar que dessem em resultado o criar uma grande atividade na instrução de uma minoria seleta de alunos em prejuízo do aproveitamento das classes mais atrasadas.

Pode censurar-se o sistema que, em verdade, praticado imprudentemente exporia ao risco de privar mais e mais de uma base sólida a instrução das últimas classes; mas duvido que se possa dizer, sem injustiça, que tenha sido pretexto a preferências menos justificadas. Creio mesmo que, durante o período de instalação, de que apenas acaba de sair a Escola, não se teriam logrado resultados numéricos mais avantajados, sem que decrescesse proporcionalmente a média da instrução individual.

Não tratarei agora de inquirir se numa escola primária se deve olhar menos para a beleza que para a quantidade dos frutos; ou se a sua missão é antes acudir à pobreza de espírito e coração do que ativar o desenvolvimento dos talentos mais salientes. Limito-me a fazer sentir o que tem tido de excecional, até ao presente, a existência da Escola. Tem dado o que devia dar; mas não pode continuar a dar o que deu nos primeiros anos, sem se esquecer da [fl. 2] sua verdadeira destinação ainda mais do que tem sido obrigada a fazêlo. Não se contentará de ser uma segunda lactação, mas não se lembrará nunca de ser um meio de propaganda. A Escola está ou, pelo menos, deve conservar-se igualmente afastada dessa simplicidade idílica como da utilidade que lhe atribuem as paixões políticas ou religiosas.

Aos pais dos alunos pediria eu que concorressem menos às festividades escolares, nas quais se expõem a dissabores que na sua mão estaria muitas vezes evitar, e frequentassem mais a aula nos dias ordinários; que não contassem só os prémios 
concedidos ou recusados no fim do ano, mas os títulos que, durante ele, dão direito a essas distinções. Tenho para mim que, se fosse possível recolher os votos das famílias e os dos alunos, estes últimos conhecedores e juízes uns dos outros, absolveriam o magistério das imputações de parcialidade com que se costuma comentar a solenidade que hoje celebramos. Nem todas as queixas supõem razão ou injustiça, e não faltaria a si mesma escola, desatendendo as que procedem de uma apreciação inexata e impaciente das aparências.

Questões de método os resultados, e só os resultados, podem cortá-las. Ora os resultados, até hoje, são satisfatórios, se os compararmos com o que sucede em institutos análogos. Vale sempre o método de ensino o que valer o mestre, e a liberdade em escolhêlo é das que eu concederia sem repugnância ao ensino público. A regularidade e a simetria, que tantas vezes se confunde com a primeira, são coisas que estimo, mas no seu lugar. Não me parece que possa haver ortodoxia onde há progresso, nem segurança na preferência onde é tanta a incerteza no debate.

Do que venho de dizer não se infira que eu conte entre as justas de vaidades as discussões sobre a excelência relativa dos métodos, ou que a escola deva ter-se indiferente às reclamações que têm por fundamento as pretendidas restrições opostas à concorrência.

Separando de todo os dois institutos, a cujo consórcio forçado aludi [fl. 2 v.]; dando maior largueza à instrução elementar; pondo sobretudo ao ensino os marcos miliários, que hoje Ihe faltam, e que digam ao aluno o que lhe é necessário, útil ou supérfluo aprender, entendo que se terá conseguido entrar na ordem e satisfazer os mais exigentes.

Virá desta forma a desdobrar-se o ensino segundo a sua divisão mais racional, interpondo-se de envolta uma barreira necessária entre a instrução primária elementar e a superior.

Distinguem-se, ao mesmo tempo, mais completamente que na atualidade os exercícios de memória, que na instrução da infância são tudo, dos exercícios de raciocínio, que supõem um começo de cultivo intelectual. Sem que haja precisão de alterar por modo sensível os métodos, desvanecer-se-ão assim, penso eu, os inconvenientes da reunião de um número excessivo de funções diversas numa mesma mão. Deixarão umas disciplinas de ser sacrificadas às outras; deixando a escola urbana de absorver a escola rural.

A solenidade que, para Vós, é uma festa, é para mim uma lutuosa comemoração. É hoje o aniversário da única distribuição de prémios a que presidiu a Rainha, a minha companheira, a amiga dos pobres. Nenhuma dor igual à de recordar na desgraça os tempos felizes. Orai pelo descanso de Aquela que fora Vossa protetora, que ontem ainda, flor pendida sobre o sepulcro, folgava com as vossas alegrias como eu sei que folgava.

Mafra, 26 de agosto de 1860

D. Pedro V

CARLOS MANIQUE DA SILVA é diretor do Centro de Formação da Associação de Escolas Rómulo de Carvalho e membro da Unidade de Investigação e Desenvolvimento em Educação e Formação (Instituto de Educação da Universidade de Lisboa). Foi professor visitante nas Universidades Estaduais de São Paulo e de Santa Catarina, no Brasil. As suas 
áreas de investigação estão direcionadas para a circulação e difusão do conhecimento pedagógico, a escola graduada e a arquitetura escolar.

Endereço: Rua Casal do Carantão, 10, 2655-430, Ericeira/Portugal.

E-mail:manique@net.sapo.pt

Recebido em 21 de abril de 2018.

Aceito em 26 de junho de 2018. 